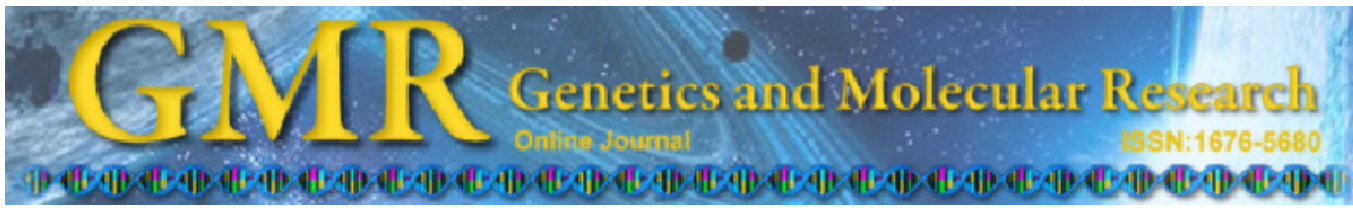

$\underline{\text { Review }}$

\title{
Genomic in situ hybridization in plants
}

\author{
G.S. Silva and M.M. Souza \\ Departamento de Ciências Biológicas, Universidade Estadual de Santa Cruz, \\ Ilhéus, BA, Brasil \\ Corresponding author: M.M. Souza \\ E-mail: souzamagg@yahoo.com.br
}

Genet. Mol. Res. 12 (3): 2953-2965 (2013)

Received April 25, 2012

Accepted July 5, 2013

Published August 12, 2013

DOI http://dx.doi.org/10.4238/2013.August.12.11

\begin{abstract}
Genomic in situ hybridization (GISH), which is a modification of fluorescent in situ hybridization, has been widely used in the study of plants. It has become one of the most important techniques for molecular cytogenetics. GISH is a technique that allows distinguishing the genomes in a cell. With this technique, it is possible to differentiate the genomes in a hybrid; consequently, this tool has been applied to the study of hybrid lineages, genetic improvement programs, and studies of the evolution of polyploids. Moreover, GISH can be applied to the analysis of the meiotic behavior in hybrids and polyploids, providing information concerning the relationship between species. This review presents the wide application of this technique in plants.
\end{abstract}

Key words: GISH; Intergeneric hybrids; Interspecific hybrids; Allopolyploids; Plant improvement 


\section{INTRODUCTION}

Until the beginning of the 1970s, the only way to analyze chromosomes was through classical cytogenetics, which was based mainly on the study of the morphology, such as the size of the arms, position of the centromeres and location of the secondary constrictions, number and alterations of chromosomes. It was possible to visualize stained chromosomes always in a uniform manner, or using banding techniques, which are not successful with some species and which do not always provide reliable results due to the difficulties in their interpretation. However, with the development of molecular cytogenetics at the end of the 1960s, which began with the research of Pardue and Gall (1969), a technique that allowed the localization of DNA-DNA hybrid molecules in cytological preparations was developed. Thus, more efficient tools were developed, aimed at the study of chromosomes in a refined way. These tools allowed the identification of sequences and regions in the chromosome that could not be analyzed through conventional cytogenetics, thereby guaranteeing more reliable results, making them useful in different approaches. Molecular cytogenetics has led to great advances in our understanding of the evolution, genetics, and karyotypic alterations in plant species (Brammer et al., 2007). This technique makes it possible to identify DNA sequences in mitotic or meiotic chromosomes, in interphase nuclei, and in extended chromatin fibers (Brasileiro-Vidal and Guerra, 2002), thereby allowing inferences on the probable chromosomal alterations that occurred in a taxon during the evolutionary process. With this new approach, a large volume of data has been generated over the last years.

The initial molecular cytogenetic techniques used radioactively labeled probes. The isotope tritium $\left[{ }^{3} \mathrm{H}\right]$ is largely used because of its low energy radiation, which guarantees better probe resolution. Other isotopes are also used, such as $\left[{ }^{125} \mathrm{I}\right],\left[{ }^{35} \mathrm{~S}\right]$, and $\left[{ }^{32} \mathrm{P}\right]$. In general, the radioactive isotope is chosen according to the resolution level desired. Currently, radioactive probes are rarely used, as they demand a long exposure time and also endanger the health of those who handle them (Guerra, 2004).

Nowadays, non-radioactive probes are used, where a label is bound to the DNA probe. The most used labeling molecules are digoxigenin and biotin, which are detected by means of fluorochromes (direct staining) or by an antibody-fluorochrome conjugate (indirect staining). With the introduction of fluorochromes, this technique became known as fluorescent in situ hybridization (FISH) (Guerra, 2004).

And a little more than the two decades ago, genomic in situ hybridization (GISH), a modification of FISH, emerged as one of the most important and versatile tools of molecular cytogenetics (Schwarzacher, 2003). While FISH uses specific DNA sequences as probes, such as the $45 \mathrm{~S}$ and $5 \mathrm{~S}$ ribosomal genes, single-copy genes, and telomeric DNA, GISH uses total genomic DNA of a species as probe. The great advance of this technique in relation to FISH is the labeling of entire genomes, making it advantageous in many studies, for example, in the identification of genomes and in meiotic analysis (Stace and Bailey, 1999). GISH has been intensely used in the identification of the genomes of genitors in natural or artificial hybrids (interspecific or intergeneric), in the origin and evolution of natural allopolyploids, and in plant improvement programs, such as the selection of genitors in genetic improvement. With this tool, direct (visual) results are obtained as regards the distinction of different genomes in a hybrid, with information being easy to analyze in a reliable manner (Wang et al., 2009).

The aim of this article is to report the use of GISH in the identification of plant genomes. 


\section{GISH technique}

GISH is used for the purpose of distinguishing chromosomes from different genitors or from different genomes in interspecific/intergeneric hybrids or allopolyploids. In this case, total genomic DNA of a genitor involved in the formation of a hybrid is used at the same time as an unlabeled DNA from another genitor, at a higher concentration, which serves as a blocking DNA, hybridizing with the sequences in common with both genomes. In GISH, the probe is easier to obtain, and may be used directly, with no need for amplification, because the amount of DNA is limitless (Peñaloza and Pozzobon, 2007). Total genomic DNA must be broken into smaller fragments, which can be done by using restriction enzymes, autoclaving, or sonicating. Although autoclaving is more often used to break DNA due to the low cost of the equipment, sonication provides greater precision as regards the size of the DNA fragments. Probe labeling may be carried out with random primers, PCR, or nick translation; however, labeling using kits for nick translation is more widely used (Guerra, 2004).

The probe/blocking DNA ratio must be enough to prevent the labeling of chromosomes of both genomes at the same time (Brammer et al., 2009). The use of blocking DNA is usually necessary in hybrids derived from close species, due to the high degree of homology shared between the species that originated the hybrid, which may enable the probe to label the genomes of both genitors indistinctly. It was necessary to use $100 \mathrm{X}$ concentrated blocking DNA in hybrids of Lycopersicon esculentum and L. peruvianum to distinguish the genomes (Parokonny et al., 1997), whereas in hybrids of Dendranthema nankingense and Tanacetum vulgare, both genomes were identified without the need of a blocking DNA (Tang et al., 2011), since species belonging to a different genus show greater genetic distance. By adjusting the blocking DNA concentration for each species, in accordance with the degree of genetic proximity, it is possible to assure that the probe stains only one of the genomes. The concentration of blocking DNA must be adjusted for each family under study. The use of unlabeled genomic DNA as blocking agent increases the specificity of the staining and prevents cross-hybridization (Anamthawat-Jónsson et al., 1990). Usually, genomes that share 80-85\% homology can be differentiated using standard GISH conditions (Schwarzacher et al., 1989). On the other hand, with the increase in stringency conditions combined with excess of blocking DNA, it is possible to differentiate genomes that share up to 90-95\% homology (Parokonny et al., 1997).

\section{Applications of GISH}

This method has been used with great success in the study of plants, in different approaches. One of the great advantages of this technique is its use as a tool to analyze meiotic behavior, that is, how chromosomes behave during the meiotic process, how pairing occurs among chromosomes, or how meiosis occurs in natural and artificial hybrids, whether pairing occurs only between homologous chromosomes or if it occurs between homeologous chromosomes. With GISH, it is possible to determine the formation rate of univalents, bivalents, and multivalents in a hybrid by relating them to genitor genomes, and also the chiasma frequency (recombination) between homeologous chromosomes. The great advantage is that with this technique it is possible to visualize which factors lead to an irregular meiosis, and how it affects fertility.

The analysis of meiotic behavior was performed by means of GISH in interspecific 
hybrids of cultivated species of bananas. The hybrids were obtained from the crossing between Musa acuminata $(2 \mathrm{n}=2 \mathrm{x}=22, \mathrm{AA})$ and $M$. balbisiana $(2 \mathrm{n}=2 \mathrm{x}=22, \mathrm{BB})$. The interspecific triploid hybrids 'Figure Pomme' $(2 \mathrm{n}=3 \mathrm{x}=33, \mathrm{AAB})$ and 'Praha' $(2 \mathrm{n}=3 \mathrm{x}=33, \mathrm{ABB})$ were observed as univalent, bivalent, and multivalent in both cultivars, with homeologous bivalents being observed in all cells analyzed; all multivalents (trivalent and tetravalents) involved homeologous chromosomes. In this study, it was possible to demonstrate the recombination between genomes A and B, which can be useful in the domestication and improvement of interspecific banana cultivars (Jeridi et al., 2011). In Brassica, GISH was used to verify the hybrids derived from the cross between the wild species $B$. maurorum $(2 \mathrm{n}=2 \mathrm{x}=16, \mathrm{MM})$ and two cultivated species, B. rapa $(2 \mathrm{n}=2 \mathrm{x}=20$, AA $)$ and $B$. napus $(2 \mathrm{n}=4 \mathrm{x}=38$, AACC $)$. The cross between $B$. maurorum and $B$. rapa originated the hybrid $(2 \mathrm{n}=18, \mathrm{MA})$, and the cross between $B$. maurorum and $B$. napus originated the hybrid $(2 \mathrm{n}=27, \mathrm{MAC})$. In this study, the genomes $\mathrm{M}, \mathrm{A}$, and $\mathrm{C}$ were unequivocally distinguished, and by analyzing meiotic behavior it was possible to observe that the majority of the chromosomes in the hybrids did not pair, thereby remaining as univalents (Yao et al., 2010).

The meiotic pairing of the chromosomes in metaphase I of allotetraploid hybrids of the cross of Lolium perenne $\mathrm{x}$ Festuca pratensis $(2 \mathrm{n}=4 \mathrm{x}=28$; FpFpLpLp) was analyzed in species involving the Lolium-Festuca complex, which have been widely studied. The autotetraploid individuals of $L$. perene $(2 \mathrm{n}=4 \mathrm{x}=28 ; L p L p L p L p)$ and $F$. pratensis $(2 \mathrm{n}=4 \mathrm{x}=28 ; F p F p F p F p)$ were obtained through the duplication of the genome of the diploid species. GISH showed that the formation of the bivalents was predominantly intragenomic (bivalents $L p / L p$ and $F p / F p$ ), and the formation of the bivalents was intergenomic $(L p / F p)$ at only $33 \%$. These data are informative and provide accurate information about the degree of intergenomic pairing and the recombination potential that may exist between two genomes of interest (Zwierzykowski et al., 2008).

In the improvement of plants, it is not always possible to obtain the plant desired at the end of a backcross, mainly due to problems that occur during meiosis, which can result in aneuploid gametes. GISH may be very useful to analyze problems that can appear during crosses in an improvement program and makes this process impracticable. GISH was used to follow the insertion of the characteristic 'pink color' of the petals of Lilium rubellum in L. longiflorum, and to verify the $\mathrm{F}_{1}$ hybrid and its backcrossed progenies $\mathrm{RC}_{1}$ and $\mathrm{RC}_{2}$; it was observed that the $\mathrm{F}_{1}$ hybrid was infertile. It was possible to determine if infertility was due to abnormal meiosis, because the majority of the chromosomes remained as univalents during meiosis and because the homeologous chromosomes that formed the bivalents had a frequency of only one chiasma; fertility cannot be reestablished by means of amphidiploidy, and, as these two species were relatively distant, there was no pairing between homeologous chromosomes, but only between homologous chromosomes. It was not possible to insert the characteristic of interest, since the homeologous chromosomes of the two species did not recombine (Lim et al., 2000).

The meiotic behavior in an introgressed line of cultivated tomato, L. esculentum 'VF$36^{\prime}(2 \mathrm{n}=2 \mathrm{x}=24)(=$ Solanum lycopersicum $)$, was analyzed by GISH; it was possible to observe the sizes of the chromosome segments of S. lycopersicoides, a species of wild tomato, introgressed in the cultivated species of the tomato L. esculentum, where larger chromosome segments produced a larger GISH signal (Ji and Chetelat, 2007).

Another application of this technique is its use as a tool for confirmation of hybrids derived from apomictic species, which can reproduce without fertilization. The occurrence of apomixis has already been reported in some species of the genus Lilium. Therefore, it is 
necessary to determine if the hybrids obtained from the cross between these species are truly hybrids. The use of GISH is one of the unequivocal ways of accomplishing this. With this tool, it was possible to distinguish the genomes in hybrids from the cross between $L$. henryi $(2 \mathrm{n}=2 \mathrm{x}=24)$ and two cultivars 'Marco Polo' $(2 \mathrm{n}=2 \mathrm{x}=24)$ and 'Expression' $(2 \mathrm{n}=2 \mathrm{x}=24)$ belonging to the genus Lilium. It was possible to identify the 12 chromosomes of a genitor in relation to the one of the other genitor in both crosses, L. henryi x 'Marco Polo' and L. henryi x 'Expression' (Marasek et al., 2004).

The phylogenetic distance between the genitor genomes reflects the blocking DNA rate necessary in the hybridization mixture in GISH. By adjusting the blocking DNA rate used in GISH, it was possible to infer the phylogenetic relationship between 7 orchid species belonging to the genus Paphiopedilum. A 10X blocking DNA rate was enough to differentiate the genitor genomes from the hybrids resulting from the crosses $P$. delenatii $\mathrm{x} P$. callosum and $P$. delenatii $\mathrm{x} P$. glaucophyllum, whereas a $30 \mathrm{X}$ blocking DNA rate was necessary to differentiate the DNA of the genitors in the hybrids resulting from the following crosses: P. delenatii $\mathrm{x}$ $P$. rothschildianum, $P$. rothschildianum $\times$ P. micranthum, $P$. rothschildianum $\times$ P. bellatulum, and $P$. rothschildianum $\times$ P. moquetteanum; and a $50 \mathrm{X}$ blocking DNA rate was necessary to differentiate the genitor genomes in the hybrid resulting from the cross $P$. delenatii $\times$ P. bellatulum, suggesting that these species are remotely distant. However, it was not possible to differentiate the genomes from the genitors in the hybrid resulting from the cross $P$. delenatii $\mathrm{x}$ P. micranthum, suggesting that these species are very close within the genus (Lee et al., 2011).

\section{Interspecific hybrids}

The production of interspecific hybrids is very frequent in plants, mainly when the aim is to develop new cultivars or to introduce a characteristic of interest in plants suitable for cultivation, which is always for improvement, such as resistance to pathogens, greater yield, and others. GISH has been widely used with the rice genus Oryza. Through the cytogenetic analysis of a hybrid belonging to the genus Oryza, it was possible to differentiate genome A from genome B using GISH. The genus Oryza has two cultivated species, $O$. sativa and $O$. glaberrima, and more than 20 wild species that may be used as a genetic material source. In the hybrid resulting from the cross between the cultivated species $O$. sativa $(2 \mathrm{n}=2 \mathrm{x}=24, \mathrm{BB})$ and the wild species $O$. meyeriana $(2 \mathrm{n}=2 \mathrm{x}=24, \mathrm{GG})$, the genomes of the two genitors were easily identified, showing a considerable divergence between the two species. The genome in the hybrid derived from $O$. meyeriana showed a significantly larger size, which was analyzed by classical cytogenetics. Its larger size was found to be due to the larger amount of heterochromatin (Xiong et al., 2006). Hybrids resulting from the cross between $O$. sativa $(2 \mathrm{n}=2 \mathrm{x}=$ $24, \mathrm{BB})$ and 3 wild species, O. rufipogon $(2 \mathrm{n}=2 \mathrm{x}=24, \mathrm{AA})$, O. officinalis $(2 \mathrm{n}=2 \mathrm{x}=24, \mathrm{CC})$ and $O$. meyeriana $(2 \mathrm{n}=2 \mathrm{x}=24, \mathrm{GG})$, were also analyzed. It was not possible to differentiate the chromosomes of each donor genome using GISH in the hybrid resulting from the cross $O$. sativa x O. rufipogon. All chromosomes were stained when the genomic DNA of O. rufipogon was used without blocking DNA; however, with the increased concentration of blocking DNA the chromosomes were faintly stained. None of the chromosomes were stained when the blocking DNA was used at a probe/blocking DNA ratio of 1:40. It was not possible to differentiate the genomes of hybrids resulting from this cross, whereas it was possible to differentiate the genomes of each donor genitor in hybrids resulting from the crosses $O$. sativa $\mathrm{x} O$. officina- 
lis and O. sativa x O. meyeriana. In Oryza, the wild species have a larger genome due to the greater amount of heterochromatin, and $O$. rufipogon has a high degree of homology with $O$. sativa; therefore, it is believed that cultivated rice originated from $O$. sativa (Tan et al., 2006).

The first autotetraploid species within the genus Setaria was identified on the basis of GISH. The genomes of the diploid species $S$. adhaerens $(2 \mathrm{n}=2 \mathrm{x}=18, \mathrm{BB})$ and $S$. viridis $(2 \mathrm{n}$ $=2 \mathrm{x}=18, \mathrm{AA})$ were used as probes in the investigation of the genetic constitution of the tetraploid species $S$. queenslandica $(2 \mathrm{n}=4 \mathrm{x}=36)$. None of the chromosomes were stained when genome B of $S$. adhaerens was used as probe, whereas the 36 chromosomes were stained when genome A of $S$. viridis was used as probe. These results clearly suggest that $S$. queenslandica is an autotetraploid species with the genome constitution AAAA (Wang et al., 2009). Clivia cyrtanthiflora is an interspecific hybrid, produced by Charles Raes in the late 1980s, and refers to an ornamental cultivar, cultivated for more than 100 years in many parts of the world. Using GISH, it was possible to confirm that the individuals of C. cyrtanthiflora are in fact $\mathrm{F}_{1}$ hybrids resulting from the cross between C. miniata and C. nobilis (Ran et al., 2001).

\section{Intergeneric hybrids}

GISH was first used by Schwarzacher et al. (1989) to identify the genomes of the intergeneric hybrid between Hordeum chilense $(2 \mathrm{n}=2 \mathrm{x}=14)$ and Secale africanum $(2 \mathrm{n}=2 \mathrm{x}$ $=14$ ), demonstrating that these genomes, 7 chromosomes of $H$. chilense and 7 chromosomes of $S$. africanum, could be recognized in the mitotic metaphase and during the cell cycle, occupying different domains in the interphase nucleus. This trend of the genomes of not mixing inside the nucleus, forming domains, can influence important functions in the cell, such as gene expression. Since the chromosomes may be stained during the cell cycle, this technique has the potential to supply information on the organization and space distribution of the genomes (Leitch et al., 1991).

In the production of somatic hybrids $(2 \mathrm{n}=4 \mathrm{x}=36)$ resulting from the cross between Citrus auratium $(2 \mathrm{n}=2 \mathrm{x}=18)$ and Poncirus trifoliata $(2 \mathrm{n}=2 \mathrm{x}=18)$, it was possible to distinguish the 18 chromosomes from each donor species by the GISH technique, also observing the presence of recombinant chromosomes between the two genomes in one plant (Fu et al., 2004).

GISH has been widely used in the study of hybrids of the family Brassicaceae. The use of GISH combined with classical cytogenetics to study the intergeneric somatic hybrid $\mathrm{x}$ Brassicoraphanus $(2 \mathrm{n}=2 \mathrm{x}=38)$, derived from the cross between Brassica campestris ssp pekinensis $(2 \mathrm{n}=2 \mathrm{x}=20)$ and Raphanus sativus $(2 \mathrm{n}=2 \mathrm{x}=18)$, clearly identified that in the hybrid, 20 chromosomes were from Brassica and 18 chromosomes were from Raphanus (Lim et al., 2012). GISH analysis of the new cultivars from the cross between Littonia modesta (2n $=2 \mathrm{x}=22)$, Sandersonia aurantiaca $(2 \mathrm{n}=2 \mathrm{x}=24)$ and 3 cultivars belonging to the genus Gloriosa, G. superba 'Lutea' $(2 \mathrm{n}=2 \mathrm{x}=22)$, G. superba 'Marrom Gold' $(2 \mathrm{n}=4 \mathrm{x}=44)$, and G. superba 'Verschild' $(2 \mathrm{n}=7 x=77)$ demonstrated that in the 9 hybrids from intergeneric crosses involving the 3 genera, the genomes of the genitors were distinctly identified and there was no cross-hybridization, suggesting that the degree of homology between these 3 genera is relatively low, and that these genera diverged in the early evolutionary process (Nakazawa et al., 2011).

An intergeneric hybrid $(2 \mathrm{n}=2 \mathrm{x}=18)$, which was later cytogenetically analyzed using GISH, was obtained from the intergeneric cross between D. nankingense $(2 \mathrm{n}=2 \mathrm{x}=18)$ and 
T. vulgare $(2 \mathrm{n}=2 \mathrm{x}=18)$. Analysis with GISH successfully distinguished the chromosomes of $D$. nankingense from those of $T$. vulgare in the hybrid without blocking DNA. This ease of differentiating the chromosomes of these two species confirms that they are genetically distant, which makes the generation of intergeneric hybrids difficult (Tang et al., 2011). Also, as regards the report on the first intergeneric hybrid $(2 n=3 x=27)$ involving the tetraploid species D. indicata $(2 \mathrm{n}=4 \mathrm{x}=36)$ and the diploid species Crossostephium chinense $(2 \mathrm{n}=2 \mathrm{x}=$ 18), GISH allowed 18 chromosomes from the tetraploid species to be distinguished in relation to 9 chromosomes of the diploid species, without blocking DNA, which suggested a distant phylogenetic relationship between these two species (Tang et al., 2010).

In the analyzes of 8 hybrids resulting from the cross between tomatoes, L. esculentum x S. lycopersicoides as regards the composition of the chromosomes, using the GISH technique, it was possible to distinguish accurate groups of chromosomes derived from each genitor, namely 4 tetraploid hybrids $(2 n=4 x=48)$ and 4 hexaploid hybrids $(2 n=6 x=72)$. There was a set of tomato chromosomes ( 24 chromosomes) and a set of $S$. lycopersicoides chromosomes ( 24 chromosomes) in the tetraploid hybrids, whereas in hexaploid hybrids there were two sets of tomato chromosomes (48 chromosomes) and one set of $S$. lycopersicoides chromosomes ( 24 chromosomes). This difference in the chromosome sets of tetraploid and hexaploid hybrids may have influenced the apparent variation of the foliar morphology (Escalante et al., 1998).

\section{Origin and evolution of allopolyploids}

Polyploidy is considered the main evolutionary route in plants. It is estimated that more than $70 \%$ of angiosperms are polyploids (Wendel, 2000; Soltis and Soltis, 2000), resulting from both autopolyploidy and allopolyploidy, that is, polyploidy is considered the main force in the evolution of the genomes of plants. However, allopolyploid plants, where two or more different genomes are involved, are more frequent, as these plants have a higher degree of variability, favoring the best adaptation process throughout the evolutionary process (Soltis and Soltis, 2000).

The GISH technique can be used to better understand the origin and evolution of allopolyploids, and it can be applied when there is suspicion of an allopolyploid origin (Guerra, 2004). In the study of allopolyploids, the DNA of the probable donors is transformed into probes and used to hybridize with the allopolyploid plant; if a set of chromosomes (genome) is stained, then this plant was one of the probable donors for the formation of this allopolyploidy. An allopolyploid plant may have genomes of two or more donors that can be unequivocally differentiated by means of GISH, making this an important tool to understand the evolution of plants.

The efficiency of the GISH technique for the detection of allopolyploids was demonstrated in Camellia reticulata, globally known for its ornamental nature. In this species, where polyploids with $2 \mathrm{x}=30,4 \mathrm{x}=60$, and $6 x=90$ are found, with the basic chromosome number $x=15$, previous studies indicated that polyploid individuals were allopolyploids. With the use of GISH is was possible to prove the allopolyploid origin of this species, demonstrating that C. reticulata $(4 x)$ resulted from the cross between $C$. reticulata $(2 x)$ and $C$. pitardii $(2 x)$, and that $C$. reticulata $(6 x)$ was the result of a subsequent cross between $C$. reticulata $(4 x)$ and $C$. saluenensis (2x) (Liu and $\mathrm{Gu}, 2011)$. 
The genitors Begonia longifolia and B. palmata were identified by GISH in the natural allodiploid hybrid Begonia x chungii $(2 \mathrm{n}=22)$. However, when the DNA of any one of the genitors was used as probe, 16 chromosomes were stained in the natural hybrid, instead of 11 chromosomes, as expected (Kono et al., 2012). Simultaneously, 16 chromosomes, instead of 11 , were stained in an artificial $\mathrm{F}_{1}$ hybrid between B. longifolia and B. palmata (Kono et al., 2012). By means of meiotic studies, it was observed that these two species have a recent common ancestor, and that each one has 6 specific chromosomes and 5 shared chromosomes between the two species; therefore, 16 chromosomes were stained instead of 11 .

The relationship between 6 commercially important species of Brassica - 3 diploids and 3 allopolyploids - was shown by means of classical cytogenetic studies. This relationship is usually referred to as the "U triangle", where the cross between $B$. oleracea $(2 n=2 x=18$, $\mathrm{CC})$ and $B$. rapa $(2 \mathrm{n}=2 \mathrm{x}=20, \mathrm{AA})$ originated the allotetraploid species $B$. napus $(2 \mathrm{n}=4 \mathrm{x}=$ 38 , AACC); the cross between $B$. nigra $(2 \mathrm{n}=2 \mathrm{x}=16, \mathrm{BB})$ and B. oleracea $(2 \mathrm{n}=2 \mathrm{x}=18, \mathrm{CC})$ originated the allotetraploid species $B$. carinata $(2 \mathrm{n}=4 \mathrm{x}=34, \mathrm{BBCC})$; and the cross between $B$. rapa $(2 \mathrm{n}=2 \mathrm{x}=20, \mathrm{AA})$ and $B$. nigra $(2 \mathrm{n}=2 \mathrm{x}=16, \mathrm{BB})$ originated the allotetraploid species $B$. juncea $(2 \mathrm{n}=4 \mathrm{x}=36, \mathrm{AABB})$. The genomes of the allotetraploid species $B$. juncea and $B$. carinata were unequivocally distinguished in two studies using GISH, but the genomes of B. napus could not be distinguished (Snowdon et al., 1997; Hasterok et al., 2005). Later, a third study of the allotetraploid species B. napus using the GISH technique allowed genomes $\mathrm{A}$ and $\mathrm{C}$ of this species to be clearly distinguished (Howell et al., 2008).

In the GISH analysis of 3 natural allopolyploidy species of tobacco, Nicotiana rustica $(2 \mathrm{n}=4 \mathrm{x}=48), N$. arentsii $(2 \mathrm{n}=4 \mathrm{x}=48)$ and $N$. tabacum $(2 \mathrm{n}=4 \mathrm{x}=48)$, it was found that the donor species of $N$. rustica were ancestral species related to $N$. paniculata $(2 \mathrm{n}=2 \mathrm{x}=24)$ and $N$. undulata $(2 \mathrm{n}=2 \mathrm{x}=24)$. The donor species of $N$. arentsii were ancestors related to $N$. undulata $(2 \mathrm{n}=2 \mathrm{x}=24)$ and $N$. wigandioides $(2 \mathrm{n}=2 \mathrm{x}=24)$. The donor species of $N$. tabacum was closely related to $N$. sylvestris $(2 \mathrm{n}=2 \mathrm{x}=24)$, donor of the maternal genome, and probably $N$. tomentosiformis $(2 \mathrm{n}=2 \mathrm{x}=24)$, donor of the paternal genome (Lim et al., 2004).

In the genus Eleusine, the case of E. coracana was solved using GISH. Cytogenetic studies showed that $E$. coracana is an allotetraploid, and that the wild diploid species $E$. indica, E. floccifolia, E. intermedia, E. tristachya, and E. verticillata are their putative genitors. A study was carried out with the species E. indica $(2 \mathrm{n}=2 \mathrm{x}=18)$, E. tristachya $(2 \mathrm{n}=2 \mathrm{x}=18)$, E. floccifolia $(2 \mathrm{n}=2 \mathrm{x}=18)$, E. intermedia $(2 \mathrm{n}=2 \mathrm{x}=18)$, E. multiflora $(2 \mathrm{n}=2 \mathrm{x}=16)$, and $E$. jaegeri $(2 \mathrm{n}=2 \mathrm{x}=20)$ to try to find out which ones of these species donated their genome to E. coracana $(2 \mathrm{n}=4 \mathrm{x}=36)$. The genomic DNA of E. multiflora and E. jaegeri used as probes did not stain any of the chromosomes of E. coracana; when the genomic DNA of $E$. indica and E. floccifolia were used, both stained 18 chromosomes of E. coracana, suggesting that these species are donors of the genomes of E. coracana (Bisht and Mukai, 2001).

The mango (Mangifera indica L.; $2 \mathrm{n}=40$ ) is a commercially important fruit that belongs to the genus Mangifera (family Anacardiaceae). GISH was used to understand the relationship between Mangifera indica and 8 wild species belonging to the genus Mangifera. It was possible to distribute the 8 species into 4 groups according to the degree of hybridization (homology) with Mangifera indica. In group 1 (M. sylvatica, M. flava, and M. caloneura), all probes strongly stained not only the centromeric and telomeric regions but also several regions on the chromosomes. In group 2 (M. cochinchinensis and M. foetida), the number and intensity of stained areas were lower in relation to the first group. In group 3 (M. gracilipes), 
the species displayed weak staining. There were no stained species in group 4 (M. griffithii and M. macrocarpa). Thus, the species belonging to group 1 are closely related, whereas species of group 4 are more distant from $M$. indica (Nishiyama et al., 2006).

The hybrid nature of the species Emilia fosbergii $(2 \mathrm{n}=4 \mathrm{x}=20)$, considered as a natural allotetraploid, was analyzed with GISH. This species shows a bimodal karyotype, with 10 larger chromosomes and 10 smaller chromosomes; these subgroups of chromosomes are considered as coming from different ancestors. When the genomic DNA from $E$. fosbergii was used as probe, and the DNA from E. sonchifolia $(2 \mathrm{n}=2 \mathrm{x}=10)$ was used as blocking DNA, only the subgroup with larger chromosomes was strongly stained, indicating that the subgroup of smaller chromosomes were derived from E. sonchifolia (Moraes and Guerra, 2010).

In an attempt to elucidate the amphidiploid nature of Aster microcephalus var. ovatus $(2 \mathrm{n}=36)$, the karyological analysis combined with the morphological characteristics, followed by artificial cross, suggested that $A$. microcephalus var. ovatus was a tetraploid amphidiploid species. Using the GISH technique and the genomic DNA of $A$. iinumae $(2 \mathrm{n}=18)$ and $A$. ageratoides $(2 \mathrm{n}=18)$, without blocking DNA, it was possible to confirm that $A$. microcephalus var. ovatus was a tetraploid amphidiploid formed by the combination of the genomes of these two species (Matoba et al., 2007).

The peanut, Arachis hypogaea $(2 \mathrm{n}=4 \mathrm{x}=40, \mathrm{AABB})$, is a species well established as an allotetraploid. Using the GISH technique, 7 diploid wild species were analyzed $(2 \mathrm{n}=$ $20)$ to verify the probable donors of genomes A and B of the peanut. Among the species used, A. duranensis (genome A) and A. ipaensis (genome B), showed the most uniform and intense hybridization pattern. Therefore, they were considered the best candidates to be the donors of the genomes of $A$. hypogaea (Seijo et al., 2007).

Some factors keep the GISH technique from being $100 \%$ efficient in determining the interspecific and even intergeneric parental genomes, such as the strong genetic proximity between the analyzed species, or the high transposon rate. The history of the hybrid nature of maize has been studied for a long time, but recent molecular studies have confirmed the allotetraploid nature of maize (Zea mays ssp mays, $2 \mathrm{n}=4 \mathrm{x}=20$ ) (Moore et al., 1995; Gaut and Doebley, 1997). However, the probable ancestral species of modern maize remains unknown. With the use of GISH, attempts were made to identify the probable maize diploid ancestors using the DNA of 10 wild species close to maize as probe. However, none of the probes stained a set of chromosomes, as expected, with only dispersed staining all over the genome. The probable explanations are: the species used are very close; none of the species used represent the maize ancestor; the genomes mixed very quickly after polyploidization due to the high transposon rate (Takahashi et al., 1999).

Previous studies indicate that Miscanthus giganteus $(2 \mathrm{n}=3 \mathrm{x}=57)$ is formed by the combination of the genomes of $M$. sinensis $(2 \mathrm{n}=2 \mathrm{x}=38)$ and $M$. sacchariflorus $(2 \mathrm{n}=2 \mathrm{x}=38)$. To analyze the hybrid allopolyploid origin of this species, GISH and ITS sequences and AFLP analysis combined showed that although the ITS sequences and AFLP analysis clearly demonstrated that M. giganteus possessed the genomes of M. sinensis and M. sacchariflorus, it was not possible to distinguish the genomes using GISH. The use of M. sinensis and M. sacchariflorus as probes resulted in dispersed staining of all chromosomes (Hodkinson et al., 2002).

In the genus Nothoscordum, some of the variants of $N$. gracile are intermediates between $N$. nudicaule and $N$. macrostemon, which together with $N$. gracile, make part of the Inodorum complex. To elucidate the hybrid nature of $N$. gracile, the two species ( $N$. nudicaule 
and $N$. macrostemon) were used as probe for GISH, resulting in uniform staining of the chromosomes. Even at different blocking DNA concentrations (1X, 25X, 50X, and 75X), staining remained the same. The fact that this complex is very new may have been the reason that GISH was unable to distinguish the genomes belonging to the Inodorum complex, making it possible to produce viable hybrids between N. nudicaule and N. macrostemon (Souza et al., 2012).

\section{Improvement of plants}

The transfer of genes that confer resistance to diseases, extreme temperatures, and other adverse climatic factors, from wild species to cultivated species, is the central objective in the improvement of plants. The great utility of the GISH technique is that it makes possible to identify the chromosome where the DNA sequence of the wild species was inserted in the cultivated species, that is, the introgression of genes in cultivated species can be visualized and followed by means of GISH, as it is possible to locate the chromosome that has the introgressed sequence. A study was carried out with the $\mathrm{F}_{1}$ hybrids and its backcrossed lines for analyzing the two species Lolium multiflorum and Festuca arundinacea, which make up part of the Lolium/Festuca complex. With the use of GISH, it was possible to demonstrate that the backcrossed plant $L$. multiflorum had the introgression of a chromosomal sequence of $F$. arundinacea located in the short arm of chromosome 2, which conferred greater drought resistance (Humphreys and Pasakinskiene, 1996).

The characterization of genomes with GISH can play an important role in the selection of hybrids with potentially useful characteristics during the initial cross stages, as well as characterizing new cultivars. In hybrids of Festuca $\mathrm{x}$ Lolium, the high frequency of intergeneric recombination and the ease by which interchromosomal transfers can be detected by GISH, make this tool attractive to verify introgression and to physically map the genes of interest (Kopecký et al., 2008).

The use of GISH using the genomic DNA of rye (Secale cereale) confirmed the presence of the translocation 1BL.1RS in the wheat line PF 839197. This translocation of the chromosome arm 1RS of rye in cultivars of wheat positively affects its performance and confers resistance against insects and the attack of pathogens (Brasileiro-Vidal et al., 2005). In the wheat line ZT, it was possible to determine the presence of two resistance genes deriving from Thinopyrum intermedium: one involving the translocation of chromosome 7D, called T7DS.7DL-7Ai\#1L, carrying the $B d v 2$ gene that confers resistance to BYDV-PAV, and the chromosome 2 pair, called $2 \mathrm{Ai} \mathrm{z}$, which also carried the resistance gene to BYDV-PAV (Jahier et al., 2009). Using multicolor GISH, it was possible to characterize the resistant wheat lines, Z1, Z2, Z3, Z4, Z5, and Z6, derived from the cross of wheat $\mathrm{x}$ T. intermedium, as to the presence of chromosomes of T. intermedium or from the translocations involving the two species (Han et al., 2003). Refer to Chen (2005) for a comprehensive review on the use of Thinopyrum as a source of genetic material for improvement of wheat.

The genomic composition of Darwin hybrid tulips from the cross between Tulipa gesneriana $(2 \mathrm{n}=2 \mathrm{x}=24)$ and T. fosteriana $(2 \mathrm{n}=2 \mathrm{x}=24)$ was determined by GISH. Twentythree $\mathrm{F}_{1}$ hybrids, $14 \mathrm{RC} 1$, and $32 \mathrm{RC} 2$ were used; all plants used were diploids $(2 \mathrm{n}=2 \mathrm{x}=$ 24 ), with the exception of plant BC2 (tetrapoid, $2 \mathrm{n}=4 \mathrm{x}=48$ ) and plant BC2 (aneuploid, $2 \mathrm{n}=$ $2 \mathrm{x}+1=25$ ). GISH could distinguish the genomes from both ancestors and the intergenomic recombinations (Marasek-Ciolakowska et al., 2012). 


\section{ACKNOWLEDGMENTS}

Research supported by Coordenação de Aperfeiçoamento de Pessoal de Nível Superior (CAPES) in the form of a scholarship for G.S. Silva.

\section{REFERENCES}

Anamthawat-Jónsson K, Schwarzacher T, Leitch AR, Bennett MD, et al. (1990). Discrimination between closely related Triticeae species using genomic DNA as a probe. Theor. Appl. Genet. 79: 721-728.

Bisht MS and Mukai Y (2001). Genomic in situ hybridization identifies genome donor of finger millet (Eleusine coracona). Theor. Appl. Genet. 102: 825-832.

Brammer SP, Zanotto M and Caverzan A (2007). Citogenética Vegetal: da Era Clássica a Molecular. Embrapa Trigo, Passo Fundo. Available at [http://www.cnpt.embrapa.br/biblio/do/p_do85.htm]. Accessed December 7, 2012.

Brammer SP, Poersch LB, Oliveira AR, Vasconcelos S, et al. (2009). Hibridização Genômica in situ em Triticeae: Um Enfoque Metodológico. Embrapa Trigo, Passo Fundo. Available at [http://www.cnpt.embrapa.br/biblio/co/p_co270. htm]. Accessed December 7, 2012.

Brasileiro-Vidal AC and Guerra M (2002). Citogenética Molecular em Cereais. In: Atualização em Técnicas Celulares e Moleculares Aplicadas ao Melhoramento Genético Vegetal (Brammer SP and Iorczeski EJ, Org.). Embrapa Trigo, Passo Fundo, 277-298.

Brasileiro-Vidal AC, Cuadrado A, Brammer SP, Benko-Iseppon AM, et al. (2005). Molecular cytogenetic characterization of parental genomes in the partial amphidiploid Triticum aestivum x Thinopyrum ponticum. Genet. Mol. Biol. 28: 308-313.

Chen Q (2005). Detection of alien chromatin introgression from Thinopyrum into wheat using S genomic DNA as a probe - a landmark approach for Thinopyrum genome research. Cytogenet. Genome Res. 109: 350-359.

Escalante A, Imanishi S, Hossain M, Ohmido N, et al. (1998). RFLP analysis and genomic in situ hybridization (GISH) in somatic hybrids and their progeny between Lycopersicon esculentum and Solanum lycopersicoides. Theor. Appl. Genet. 96: 719-726.

Fu CH, Chen CL, Guo WW and Deng XX (2004). GISH, AFLP and PCR-RFLP analysis of an intergeneric somatic hybrid combining Goutou sour orange and Poncirus trifoliata. Plant Cell Rep. 23: 391-396.

Gaut BS and Doebley JF (1997). DNA sequence evidence for the segmental allotetraploid origin of maize. Proc. Natl. Acad. Sci. U. S. A. 94: 6809-6814.

Guerra M (2004). Hybridization in situ: Princípios Básicos. In: FISH: Conceitos e Aplicações na Citogenética (Guerra M, ed.). Sociedade Brasileira de Genética, Ribeirão Preto, 1-32.

Han FP, Fedak G, Benabdelmouna A, Armstrong K, et al. (2003). Characterization of six wheat x Thinopyrum intermedium derivatives by GISH, RFLP, and multicolor GISH. Genome 46: 490-495.

Hasterok R, Ksiazczyk T, Wolny E and Maluszynska J (2005). FISH and GISH analysis of Brassica genomes. Acta Biol. Cracov. 47: 185-192.

Hodkinson TR, Chase MW, Takahashi C, Leitch IJ, et al. (2002). The use of dna sequencing (ITS and trnL-F), AFLP, and fluorescent in situ hybridization to study allopolyploid Miscanthus (Poaceae). Am. J. Bot. 89: 279-286.

Howell EC, Kearsey MJ, Jones GH, King GJ, et al. (2008). A and C genome distinction and chromosome identification in Brassica napus by sequential fluorescence in situ hybridization and genomic in situ hybridization. Genetics 180: 1849-1857.

Humphreys MW and Pasakinskiene I (1996). Chromosome painting to locate genes for drought resistance transferred from Festuca arundinacea into Lolium multiflorum. Heredity 77: 530-534.

Jahier J, Chain F, Barloy D, Tanguy AM, et al. (2009). Effect of combining two genes for partial resistance to Barley yellow dwarf virus-PAV (BYDV-PAV) derived from Thinopyrum intermedium in wheat. Plant Pathol. 58: 807-814.

Jeridi M, Bakry F, Escoute J, Fondi E, et al. (2011). Homoeologous chromosome pairing between the A and B genomes of Musa spp. revealed by genomic in situ hybridization. Ann. Bot. 108: 975-981.

Ji Y and Chetelat RT (2007). GISH analysis of meiotic chromosome pairing in Solanum lycopersicoides introgression lines of cultivated tomato. Genome 50: 825-833.

Kono Y, Chung MC and Peng CI (2012). Identification of genome constitutions in Begonia x Chungii and its putative parents, B. longifolia and B. palmata, by genomic in situ hybridization (GISH). Plant Sci. 185: 156-160.

Kopecký D, Lukaszewski AJ and Doležel J (2008). Cytogenetics of Festulolium (Festuca x Lolium hybrids). Cytogenet. Genome Res. 120: 370-383. 
Lee YI, Chang FC and Chung MC (2011). Chromosome pairing affinities in interspecific hybrids reflect phylogenetic distances among lady's slipper orchids (Paphiopedilum). Ann. Bot. 108: 113-121.

Leitch AR, Schwarzacher T, Mosgöller W, Bennett MD, et al. (1991). Parental genomes are separated throughout the cell cycle in a plant hybrid. Chromosoma 101: 206-213.

Lim KY, Matyasek R, Kovarik A and Leitch AR (2004). Genome evolution in allotetraploid Nicotiana. Biol. J. Linn. Soc. 82: 599-606.

Lim SJ, Lee SS and Bang JW (2012). Karyotype and genomic in situ hybridization pattern in xBrassicoraphanus, an intergeneric hybrid between Brassica campestris ssp. pekinensis and Raphanus sativus. Plant Biotechnol. Rep. 6: $107-112$.

Lim KB, Chung JD, van Kronenburg BC, Ramanna MS, et al. (2000). Introgression of Lilium rubellum Baker chromosomes into L. longiflorum Thunb.: a genome painting study of the $\mathrm{F}_{1}$ hybrid, $\mathrm{BC}_{1}$ and $\mathrm{BC}_{2}$ progenies. Chromosome Res. 8: 119-125.

Liu LQ and Gu ZJ (2011). Genomic in situ hybridization identifies genome donors of Camellia reticulata (Theaceae). Plant Sci. 180: 554-559.

Marasek-Ciolakowska A, He H, Bijman P, Ramanna MS, et al. (2012). Assessment of intergenomic recombination through GISH analysis of F1, BC1 and BC2 progenies of Tulipa gesneriana and T. fosteriana. Plant Syst. Evol. 298: 887-899.

Marasek A, Hasterok R, Wiejacha K and Orlikowska T (2004). Determination by GISH and FISH of hybrid status in Lilium. Hereditas 140: 1-7.

Matoba H, Soejima A and Hoshi Y (2007). Identification of parental genomes and genomic organization in Aster microcephalus var. ovatus. J. Plant Res. 120: 585-593.

Moore G, Devos KM, Wang Z and Gale MD (1995). Cereal genome evolution. Grasses, line up and form a circle. Curr. Biol. 5: 737-739.

Moraes AP and Guerra M (2010). Cytological differentiation between the two subgenomes of tetraploid Emilia fosbergii Nicolson and its relationship with E. sonchifolia (L.) DC. (Asteraceae). Plant Syst. Evol. 287: 113-118.

Nakazawa D, Kishimoto T, Sato T, Saito T, et al. (2011). Genomic in situ hybridization (GISH) analysis of intergeneric hybrids in Colchicaceae. Euphytica 181: 197-202.

Nishiyama K, Choi YA, Honsho C, Eiadthong W, et al. (2006). Application of genomic in situ hybridization for phylogenetic study between Mangifera indica L. and eight wild species of Mangifera. Sci. Hort. 110: 114-117.

Pardue ML and Gall JG (1969). Molecular hybridization of radioactive DNA to the DNA of cytological preparations. Proc. Natl. Acad. Sci. U. S. A. 64: 600-604.

Parokonny AS, Marshall JA, Bennett MD, Cocking EC, et al. (1997). Homoeologous paring and recombination in backcross derivatives of tomato somatic hybrids [Lycopersicon esculentum $(+)$ L. peruvianum]. Theor. Appl. Genet. 94: 713-723.

Peñaloza APS and Pozzobon MT (2007). Caracterização Citogenética de Germoplasma Vegetal. In: Recursos Genéticos Vegetais (Nass LL, ed.). Embrapa Recursos Genéticos e Biotecnologia, Brasília, 308-342.

Ran Y, Hammett KRW and Murray BG (2001). Hybrid identification in Clivia (Amaryllidaceae) using chromosome banding and genomic in situ hybridization. Ann. Bot. 87: 457-462.

Schwarzacher T (2003). DNA, chromosomes, and in situ hybridization. Genome 46: 953-962.

Schwarzacher T, Leitch AR, Bennett MD and Heslop-Harrison JS (1989). In situ localization of parental genomes in a wide hybrid. Ann. Bot. 64: 315-324.

Seijo G, Lavia GI, Fernández A, Krapovickas A, et al. (2007). Genomic relationships between the cultivated peanut (Arachis hypogaea, Leguminosae) and its close relatives revealed by double GISH. Am. J. Bot. 94: 1963-1971.

Snowdon RJ, Köhler W, Friedt W and Köhler A (1997). Genomic in situ hybridization in Brassica amphidiploids and interspecific hybrids. Theor. Appl. Genet. 95: 1320-1324.

Soltis PS and Soltis DE (2000). The role of genetic and genomic attributes in the success of polyploids. Proc. Natl. Acad. Sci. U. S. A. 97: 7051-7057.

Souza LG, Crosa O, Speranza P and Guerra M (2012). Cytogenetic and molecular evidence suggest multiple origins and geographical parthenogenesis in Nothoscordum gracile (Alliaceae). Ann. Bot. 109: 987-999.

Stace CA and Bailey JP (1999). The Value of Genomic in situ Hybridization (GISH) in Plant Taxonomic and Evolutionary Studies. In: Molecular Systematics and Plant Evolution (Hollingsworth PM, Bateman RM and Gornall RJ, eds.). CRC Press, London, 199-210.

Takahashi C, Marshall JA, Bennett MD and Leitch IJ (1999). Genomic relationships between maize and its wild relatives. Genome 42: 1201-1207.

Tan GX, Xiong ZY, Jin HJ, Li G, et al. (2006). Characterization of interspecific hybrids between Oryza sativa L. and three wild rice species of China by genomic in situ hybridization. Acta Bot. Sin. 48: 1077-1083.

Tang F, Chen F, Chen S, Wang XE, et al. (2010). Molecular cytogenetic identification and relationship of the artificial 
intergeneric hybrid between Dendranthema indica and Crossostephium chinese by GISH. Plant Syst. Evol. 289: 91-99.

Tang F, Wang H, Chen S, Chen F, et al. (2011). Intergeneric hybridization between Dendranthema nankingense and Tanacetum vulgare. Sci. Hort. 132: 1-6.

Wang Y, Zhy H, Li W, Li H, et al. (2009). A novel genome of C and the first autotetraploid species in the Setaria genus identified by genomic in situ hybridization. Genet. Res. Crop Evol. 56: 843-850.

Wendel JF (2000). Genome evolution in polyploids. Plant Mol. Biol. 42: 225-249.

Xiong ZY, Tan GX, He GY, He GC, et al. (2006). Cytogenetic comparisons between A and G genomes in Oryza using genomic in situ hybridization. Cell Res. 16: 260-266.

Yao XC, Ge XH, Chen JP and Li ZY (2010). Intra- and intergenomic relationships in interspecific hybrids between Brassica (B. rapa, B. napus) and a wild species B. maurorum as revealed by genomic in situ hybridization (GISH). Euphytica 173: 113-120.

Zwierzykowski Z, Zwierzykowska E, Taciak M, Jones N, et al. (2008). Chromosome pairing in allotetraploid hybrids of Festuca pratensis $\mathrm{x}$ Lolium perenne revealed by genomic in situ hybridization (GISH). Chromosome Res. 16: 575-585. 